\title{
La policía del género y la invisibilización de la intersexualidad en el arte.
}

\section{The gender police and the invisibility of intersexuality in art.}

\section{Teresa López Sánchez}

IES Universidad Laboral, Málaga

terlopsan@gmail.com
Recibido 15/09/2020 Revisado 14/04/2021

Aceptado 14/04/2021 Publicado 30/04/2021

\section{Resumen:}

La intersexualidad, condición de estados intermedios entre macho y hembra, no solo se refiere a una cuestión de genitalidad, ya que depende de las múltiples variaciones a nivel de cromosomas, genes, hormonas y la combinación de todos estos elementos. Basándonos en todas estas variables y sus combinaciones se reconocen al menos 40 variaciones en el espectro intersex. En este estudio, realizaremos un recorrido sobre cómo la intersexualidad se ha tratado a lo largo de la historia y el reflejo que esta ha tenido en el arte, la forma en la que se ha representado, silenciado y reivindicado a través del trabajo de artistas intersexuales que han hecho de su creación una forma de empoderamiento ante la patologización, medicalización e invisibilización de sus cuerpos e identidades en aras de proteger el sistema binario de identidad de género.

Sugerencias para citar este artículo,

López Sánchez, Teresa (2021). La policía del género y la invisibilización de la intersexualidad en el arte. Tercio Creciente (Monográfico extraordinario V), (pp. 17-27), https://dx.doi.org/10.17561/rtc.extra5.5764

LÓPEZ SÁNCHEZ, TERESA. La policía del género y la invisibilización de la intersexualidad en el arte. Tercio Creciente (Monográfico extraordinario V) abril 2021, pp. 17-27, https://dx.doi.org/10.17561/rtc.extra5.5764 


\section{Abstract:}

Intersexuality, a condition of intermediate states between male and female, it is not reffering to a question of genitality, since it depends on the multiple variations speaking of chromosomes, genes, hormones and the combination of all these elements. Based on all these variables and their combinations, we are able to recognize at least 40 variations in the intersex spectrum. In this research, we will study how intersexuality has been discussed throughout history and its reflection in art, the way in which it has been represented, silenced and vindicated through the work of intersexual artists who have conceived their creation as a form of empowerment facing the pathologization, medicalization and invisibility of their bodies and identities for the sake of protecting the binary system of gender identity.

\section{Palabras Clave:}

Intersexualidad; identidad de género; sistema binario

Key words:

Intersexuality; gender identity; binary sistem

Sugerencias para citar este artículo,

López Sánchez, Teresa (2021). La policía del género y la invisibilización de la intersexualidad en el arte. Tercio Creciente (Monográfico extraordinario V), (pp. 17-27), https://dx.doi.org/10.17561/rtc.extra5.5764

LÓPEZ SÁNCHEZ, TERESA. La policía del género y la invisibilización de la intersexualidad en el arte. Tercio Creciente (Monográfico extraordinario V) abril 2021, pp. 17-27, https://dx.doi.org/10.17561/rtc.extra5.5764 


\section{¿Qué no es intersexualidad?}

\section{No es hermafroditismo}

Intersexualidad y hermafroditismo se suelen emplear como sinónimos dando lugar, entre otros, a confusión, prejuicios y perpetuación de estigmas.

El término «hermafrodita» hace referencia a una categoría propia de la biología y la zoología con la que se designan los organismos que o bien tienen ambos sexos durante toda su vida fértil (es lo que se conoce como hermafroditismo simultáneo), o bien cambian de un sexo a otro una, o incluso varias veces, a lo largo de su vida (este sería el hermafroditismo secuencial). A su vez, dentro de este tipo de hermafroditismo se puede dar el cambio protándrico, es decir, de macho a hembra, o protógino, de hembra a macho. Además, los organismos hermafroditas tienen la capacidad de producir gametos de uno u otro sexo indistintamente (si es simultáneo) o del sexo propio (si es secuencial) aunque también es un mito el que los organismos hermafroditas puedan autofecundarse a sí mismos. En la mayoría de los casos, los individuos hermafroditas requieren de un congénere para reproducirse.

\section{No es una enfermedad}

La condición de ser intersexual no responde a ningún trastorno que no sea el de no encajar en una estructura binaria que se ha asentado como la norma, dejando fuera a todxs aquellxs sujetxs que no se ciñen a un patrón que a las claras se presenta como no suficiente para explicar una realidad que es mucho más compleja.

Sin entrar en el debate sobre la identidad de género, qué es y qué significa sentirse hombre o mujer, el sistema binario flaquea ya desde su aplicación a la biología donde la intersexualidad pone de manifiesto las grietas que tiene este sistema dual, cerrado, y las grietas que tiene una sociedad donde se da prioridad a dicha construcción.

Salvaguardar el sistema por encima de atender la realidad es lo que lleva a todo un despliegue de la policía de género que patologiza y medicaliza de forma institucional aquello que se sale de la norma de dicho sistema. Porque por muy natural y biológica que sea la intersexualidad, esta es patologizada ante la necesidad urgente de poder asignarle al sujetx un sexo y, con ello, una identidad de género para poder perpetuar un sistema que no hace sino vulnerar, oprimir y borrar los amplios espectros que se salen de sus límites. 
Revista de Estudios en Sociedad, Artes y Gestión Cultural

\section{¿Qué sí es la intersexualidad?}

La intersexualidad es una condición biológica mucho más compleja que la simple reducción a que unx sujetx nazca con características físicas no definidas conforme a las de un sexo u otro.

La intersexualidad es el resultado de las múltiples variaciones a nivel de gónadas, cromosomas, genes, hormonas y la combinación de todos estos elementos. Esto da lugar a que, desde el momento de la concepción, el abanico de posibilidades en lo que a estructuras genitales internas y externas se refiere se disocie de lo binario teniendo en cuenta, además, que en la pubertad y el desarrollo hormonal el espectro de variaciones también se amplía a los caracteres sexuales secundarios.

\section{Tipos de intersexualidades}

En función de las variaciones gonadales, cromosomáticas, genéticas y hormonales pueden nacer individuxs que abarcan todo el campo de posibilidades que va desde nacer con estructuras genitales internas y externas femeninas o masculinas, pero con desarrollo deficiente de los ovarios o testículos; estructuras internas masculinas, pero externas femeninas, o al revés; genitales ambiguos... A esto hay que sumarle que, al llegar el desarrollo hormonal con la pubertad, individuxs con estructuras genitales tanto externas como internas femeninas, pueden desarrollar vello facial o que individuxs con estructuras genitales masculinas desarrollen mamas... El espectro es bastante amplio. Debemos tener en cuenta también que hay variaciones cromosomáticas que no son físicamente visibles.

Así pues, se reconocen al menos 40 variaciones en el espectro de la intersexualidad.

\section{Cifras}

Aunque no existen cifras oficiales sobre la intersexualidad, se estima que cada año nacen un $1,7 \%$ de bebés intersex. Sin embargo, y aunque este es el cálculo basado en los datos recogidos en el momento de nacimiento, la cifra de individuxs intersexuales nacidxs anualmente es mucho mayor si consideramos que en el momento del nacimiento se atiende a las estructuras sexuales externas y no es hasta que se produce un cierto desarrollo cuando se pueden apreciar diferencias con respecto a las estructuras internas o no es hasta la adolescencia cuando se desarrollan características sexuales secundarias. Puede darse el caso de que no se aprecie ningún tipo de diversidad con respecto a lo normativo porque la alteración tiene un nivel hormonal insuficiente como para que se vea reflejada físicamente.

Por este motivo, hablar de ese $1,7 \%$ es solo mencionar la parte visible de la intersexualidad. Porción que queda muy lejos de recoger la totalidad. De hecho, en las Olimpiadas de Pekín, en un estudio realizado a 626 atletas, se detectaron 22 variaciones de sexo cromosómico diferentes.

Sin embargo, y para poder hacernos una idea gráfica, ese $1,7 \%$ vendría a ser el equivalente a la cifra de pelirrojos que nacen cada año. 
ISSN: 2340-9096

https://doi.org/10.17561/rtc.extra5.5764

(1) (1)

\section{Historia}

Registro de la intersexualidad encontramos en todas las culturas a lo largo de todos los tiempos. Por cercanía cultural, cabe nombrar los tumtum del judaísmo antiguo o los khuntha en el antiguo islam. Y, cómo no, en la mitología encontramos explicaciones a la intersexualidad igual que al resto de condiciones y acontecimientos naturales. Ejemplo de ello es el mito de Hermafrodito y Sálmacis.

\section{Hermafrodito y Salmacis}

Hermafrodito se llama así por la mezcla del nombre de sus padres (Hermes y Afrodita). Llegado el momento de la adolescencia, abandonó el monte Ida en el que creció para encontrar su propio camino. Fue entonces cuando arribó a la tierra de lxs Carios; allí decidió descansar y refrescarse al encontrar un lago. Fue también allí donde se encontraba la ninfa Sálmacis que, mientras reposaba y se peinaba los cabellos, vio al joven, fuerte y rudo, quedando profundamente enamorada de él. Sálmacis se acercó a Hermafrodito en un intento de besarlo, pero ante el rechazo de este, la ninfa se alejó para, a escondidas, ver cómo su amado ya desnudo se bañaba en el lago. Fue en este momento, en el que Hermafrodito nadaba desnudo, cuando la ninfa se abalanzó sobre él en un intento de fundir sus cuerpos en uno amando desde entonces a hombres y a mujeres, sintiéndose como ambos y pareciéndose a ambos.

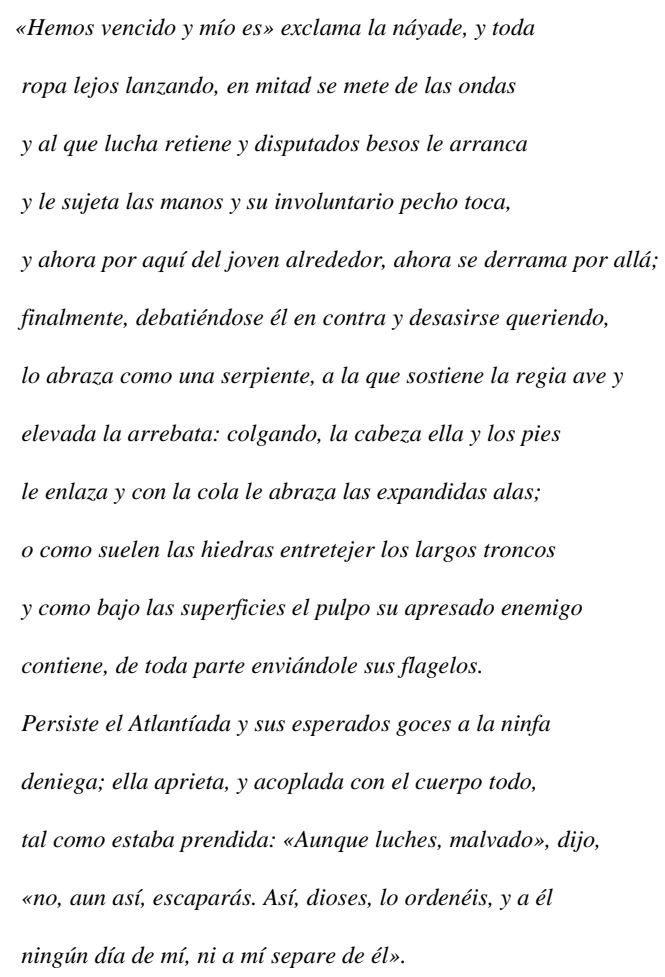

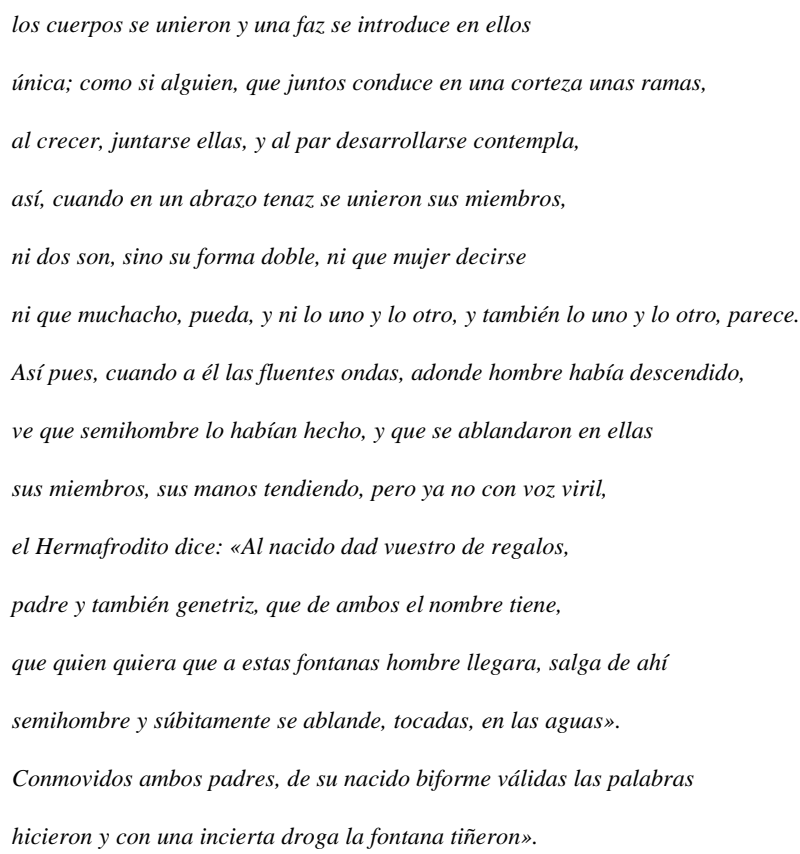

Ovidio, La metamorfósis (285 - 388) 
$\mathrm{Ni}$ que decir tiene que, con el peso del cristianismo, la intersexualidad ha quedado borrada, ocultada y estigmatizada en una sociedad donde la cisheteronormatividad se ha impuesto a base de castigar lo otro.

\section{Problemática}

Si a nivel funcional la intersexualidad no supone ningún tipo de enfermedad, ¿de dónde viene ese imperativo social por intervenir los cuerpos?

Aunque hay registros de la medicalización de los cuerpos intersexuales desde el siglo XVIII, es a partir del auge de la ciencia médica en la etapa moderna cuando se comienza a someter de forma sistemática a los recién nacidos intersexuales mediante la ablación genital y posterior construcción de un pene o vulva.

Las ablaciones, la patologización y medicalización de la intersexualidad no responde sino a la salvaguarda del sistema binario sexo/género, que llega a borrar el carácter identitario de la intersexualidad generando todo un discurso basado en falsos mitos, como la tendencia de las personas intersexuales a desarrollar un cáncer.

El riesgo de sufrir una tumoración, que no implica necesariamente el desarrollo de un cáncer, en las personas intersexuales es del $9 \%$ frente al 12,3\% de mujeres que desarrollan cáncer de mama. Así pues, si a nadie se le ocurriría realizar una mastectomía a una mujer sana por prevenir un cáncer, tampoco tiene sentido la ablación genital intersexual a personas sanas y con una genitalidad funcional. Menos aún en la infancia.

\section{Caso Money}

John Money, psicólogo especializado en psicoendocrinología, sentó las bases del estudio de la cuestión de la identidad de género desde la ciencia a través de la ablación de genitales a recién nacidos intersex y la reasignación de sexo en adultxs trans.

La tesis fundamental de Money es que lxs recién nacidxs son psicosexualmente neutros, de modo que la identidad se construye basándose en la genitalidad por asociación de roles a medida que se va produciendo el proceso de aprendizaje. Según esta tesis, la identidad de género es corregible hasta, aproximadamente, los 18 meses de vida, razón por la que, desde este posicionamiento, la ablación de genitales, aunque sanos, a personas intersex se presenta como necesaria (y cuanto más temprano, mejor) si la genitalidad de lxs individuxs no se ciñe a los parámetros de medidas estándar. 
En este proceso de desarrollo de la identidad de género, lo primero es, pues, la llamada «corrección genital».

Podemos considerar que los estudios y tesis de Money son las bases de la patologización y medicalización de la intersexualidad enfocados a diluir la identidad de las personas intersex y forzándolas a encajar en un sistema que no les da cabida. Dichas intervenciones responden a una urgencia psicosocial afirmando que, de esta manera, los individuos intersex no acarrearán la serie de problemas psicosociales y de adaptación por haber nacido con dicha condición, entendida como anómala.

En cambio, nada se dice del impacto que puede tener la construcción de neovaginas y el mantenimiento de las mismas a través de la dilatación periódica, asumiendo relaciones coitocéntricas y heterosexuales. Tampoco se tiene en cuenta el alto porcentaje de individuxs intersex que crece y se desarrolla identificándose como trans porque la ablación, la construcción de genitalidad y la educación en identidad de género de estxs sujetxs se hizo de forma cuzada por parte de la comunidad médica y la identidad sentida por el propio sujeto que, evidentemente, no tuvo oportunidad de manifestarse.

Experimento de Money ilustrado por el artista intersex Inss Frominga: https://vimeo.com/219848209

\section{El falómetro}

El falómetro fue diseñado por la Intersex Society of North America, asociación fundada en 1993 que lucha por los derechos de las personas intersex, como crítica y elemento gráfico con el que mostrar a la sociedad la forma aberrante de medir el tamaño del pene o del clítoris de lxs bebés al nacer. Fue establecido por Kira Triea combinando las tablas normativas para las longitudes tanto de penes como de clítoris, implantándose así un «área intermedia de longitud fálica que ni las hembras ni los machos tienen permitido tener». Así, a la derecha y en rosa estipularon la medida estándar que debe tener un clítoris y a la izquierda y en azul, la medida estándar del pene. Si los genitales de la persona recién nacida se encuentran en el área intermedia, lxs médicxs estipulan la necesidad de operar dichos genitales a pesar de que a nivel funcional, como venimos apuntando, no sea necesario. Se olvida con este hecho la irresponsabilidad de mutilar unos genitales que no suponen ningún problema y sin preguntarle a la persona en sí, puesto que es un bebé de apenas unas semanas de vida. Lo más respetuoso, pues, sería esperar a que el bebé creciera y se identificara con un sexo u otro, teniendo en cuenta, además, que hay otras múltiples variables que influyen en el desarrollo sexual de la persona y que se suelen manifestar en la adolescencia con el desarrollo hormonal. 


\section{Sarah Graham}

Sarah Graham es una activista intersex que trata a través de su obra el proceso de reapropiación de su cuerpo y su identidad.

Querido cuerpo, esta no va a ser una carta fácil de escribir, incluso el poner juntas estas dos sencillas palabras, "Querido" y "cuerpo", crea un conflicto dentro de mí. Tú, mi cuerpo, sabes la verdad de lo que hemos atravesado juntos, ¿no es así? 00 - 00:13

Querido cuerpo, viendo hacia atrás puedo ver a mi infancia feliz muriendo en la mesa de operaciones y, sobre ella, un cuerpo y alma con cicatrices, que después llevaban a un ser solitario cuando regresé a la escuela. 02:08 - 02:18

Bebiendo alcohol desde los doce años; cannabis, speed, ácidos, y cuanta cosa caía en mis manos a los catorce años; dos intentos de suicidio antes de cumplir los dieciséis años; relaciones de pareja peligrosas y abusivas; sexo sin protección con extraños.

Solo Dios sabe cómo he canalizado toda mi ira y temor en tratar de destruirte, querido cuerpo.

Un día, a la edad de 25 años, después de años de mentiras hacia mis padres así como a mí misma, un ginecólogo finalmente me dijo la verdadera naturaleza del diagnóstico que me dieron cuando tenía 8 años de edad, que los ovarios que quitaron de mi pequeño querido cuerpo de niña, eran en realidad testículos. Descubrí que era una mujer intersexual, en lugar de tener cromosomas XX, tenía cromosomas XY. Pero había nacido niña y tenía el certificado de nacimiento para comprobarlo, tú mi cuerpo te veías muy femenino, y yo nunca había cuestionado mi sexo; pero dentro de mí en lugar de ovarios tenía testículos, una palabra pequeña, pero que explotó dentro de mí como una bomba atómica. 02:56 - 03:52

Tomaba vodka que descendía para acallar el absoluto miedo y odio que le tenía a mi cuerpo y a los lugares traumáticos a los nos había llevado, llevándome al punto de querer una salida rápida, afortunadamente me detuvieron cuando salía por la puerta para brincar por un puente, y me metieron a rehabilitación donde estuve por 8 largos meses. 05:18 - 05:39

Sarah Graham, Letter to my body 


\section{Del Lagrance Volcano}

Pero creo que la verdadera pregunta es ¿por qué te conviertes en el tema de tu arte y cuál es tu objetivo? ¿Es recibir atención? Porque yo ya recibí mucha. Para mí, es presentarme a mí mismo con la esperanza de que otras personas como yo entiendan que sus diferencias son valiosas, que pueden salir a la luz y sentirse orgullosas y sin remordimientos, que no tienen que ajustarse.

El autorretrato, ha sido popular entre las mujeres, personas queer, y otras minorías a través del tiempo, desde Claude Cahun en el siglo pasado, hasta Zanele Moholi en la actualidad. Creo que para nosotros(as) y para mí, es porque nos damos cuenta que lo personal es político. Esta es nuestra forma de resistencia.

Del Lagrance Volcano, Pansexual

Public Porn

Los trabajos más recientes de Volcano demuestran cómo los cuerpos intersexuales pueden ofrecer una perspectiva completamente nueva sobre el cuerpo.

\section{Pidgeon Pagonis}

Toda mi vida me mintieron, y me hicieron mentir. A los 19 años descubrí que había nacido intersexual.

Pigdeon Pagonis, The son I never had. Growing up intersex

https://www.youtube.com/watch?v=i-qyd2EH7jM

\section{Cult of Rae}

https://www.instagram.com/p/B9ohUMQF8tG/ 


\section{Reflexión final}

Tras esta contextualización y visibilización de algunxs artistas interesex, solo nos queda denunciar el trato del cuerpo, la identidad y los derechos fundamentales de las personas.

En palabras de Susan Graham:

Escuchamos acerca de tribus africanas que practican clitoridectomias, pero no se escribe mucho acerca de las cirugías genitales hechas a bebés y niñxs pequeñxs para que tengan una apariencia más "normal", estas son realizadas por ginecólogos en Europa y Norte América. Es frecuente que estas operaciones se realicen por razones enteramente cosméticas, y es común que dañen la sensibilidad y respuesta sexual en la vida adulta, así como su capacidad reproductiva. Esta violación a los derechos humanos de los niños, comenzó a ser desafiada, pero las cirugías aún están sucediendo.

Susan Graham, Letter to my body.

Y, aun así, a pesar de todo, en España en 2020 la ablación genital a menores intersex solo está prohibida en la comunidad de Madrid, Aragón, Comunidad Valenciana y Baleares. 


\section{Referencias}

Alexander, T. (1997) El tratamiento médico de los niños intersexuales: un análogo del abuso sexual infantil.

Angier, N., (1997) Nuevo debate sobre la cirugía de genitales.

B. M. J. (2001) Lo que se les dice a los padres después del diagnóstico prenatal de una anomalía de los cromosomas sexuales: entrevista y estudio con cuestionario.

Cabral, M. (2009) Interdicciones: Escrituras de la Intersexualidad en castellano.

Del Lagrace, V. (1997) Pansexual Public Porn

Del Lagrace, V. (1997) A prodigal Son?

Del Lagrace, V. (1999) The Drag King Book

Del Lagrace, V. (2000) Journey Intersex

Del Lagrace, V. (2000) Sublime Mutations

Graham, S. (2011) Letter to my Body, Recuperado de: https://www.youtube.com/watch?v=nvmPeOENU_k\&t=201s

Nieto Prieto, J. A. (2008) Transexualidad, intersexualidad y dualidad de género

Ovidio, (2008) La metamorfósis 
